\title{
Exploring the Relations between Executive Functions
}

\section{and Personality}

\author{
Satish $\operatorname{Kumar}^{1} *$, Amrita Yadava ${ }^{2}$, Nov Rattan Sharma ${ }^{2}$
}

\section{ABSTRACT}

Recent academic attention in the neuropsychological groundwork of main personality factors, along with the recognition of both personality and executive functioning (EF) as major predictors of memory related problems, suggest the requirement of examining personality-EF connections. The main intend of this study was to probe into the associations between personality traits and executive functioning (i.e. Motivational Drive, Strategic Planning, Organization, Impulse Control, and Empathy). To fulfill the purpose of the study a sample consisting of approximately 50 graduate students were taken from Maharshi Dayanand University, Rohtak by using incidental sampling technique. The age range of the sample varied from 20 to 30 years. The participants were administered Executive Function Index (EFI) and NEO-FFI. The data was analyzed by using appropriate statistical analysis in order to delineate the relation between the variables under study. There are found positive significant associations on extraversion, openness and conscientiousness with executive functions. Neuroticism is found to be negatively correlated with executive functions. A notable contribution of Conscientiousness to executive functions among students is observed.

Keywords: Personality, Executive Functions.

Executive functions are vital for successful adjustment and performance in real-life conditions. They allow community to commence and complete tasks and to carry on in the face of challenges. Because the surroundings can be changeable, executive functions are essential to human ability to identify the meaning of unexpected circumstances and to make alternative sketch quickly when unusual happenings arise and interfere with usual routines. In this manner, executive function donates to success in workplace and school and permits people to handle the stresses of daily life. Executive functions also allow people to restrain inappropriate behaviors. Person with poor executive functions frequently have difficulties in dealing with others since they may say or do things that are strange or offensive to others. The majority of people

\footnotetext{
${ }^{1}$ Research Scholar, Department of Psychology, Maharshi Dayanand University, Rohtak

${ }^{2}$ Professor, Department of Psychology, Maharshi Dayanand University, Rohtak

*Responding Author

(C) 2016 I S Kumar, A Yadava, N Sharma; licensee IJIP. This is an Open Access Research distributed under the terms of the Creative Commons Attribution License (http://creativecommons.org/licenses/by/2.0), which permits unrestricted use, distribution, and reproduction in any Medium, provided the original work is properly cited.
} 


\section{Exploring the Relations between Executive Functions and Personality}

experience urges to do or say things that could get them in problems, such as making a sexually open remark to a stranger, commenting negatively on someone's look, or insulting a powerful figure like a boss or police officer; but most people have no difficulty in suppressing these urges. When executive functions are damaged, however, these strong powerful and wishful desires may not be controlled. Executive functions are thus a significant factor of the ability to fit in the society. Executive functions are vital for goal-directed behavior and have been associated with a number of main constructs of personality. Executive functions (EF) refer to the set of generalpurpose control processes that adjust thought and action in a wide variety of circumstances.

Present research outlines the relationship between a range of personality traits and a range of Executive functions. Given the span of functions believed to be connected to Executive functions, one may think that these individual diversities would be related to differences in executive functioning. Personality is the basis of what makes us unique individual. It is considered a characteristic way of thinking, feeling and behaving across different situations and events. Empirically and theoretically, it proves that personality is related to cognitive processes counted under the heading of executive functions. Furthermore, a connection come outs to be in such a way that individual differences in executive function correspond with differences in personality traits. Moreover, as research point out a different relationship may exist between the two factors of performance on attention and executive function tasks and psychopathic personality traits (Carlson, Thai \& McLarnon, 2009).

Recent research has in fact reported several associations between potentially executive functions -related behaviors and personality. For example, impulsivity has been associated with many personality traits (Whiteside \& Lynam, 2001). However, although it looks like that individual dissimilarity systems as broad and multifaceted as EF and personality would be attached in some manner, data related these precise connections are relatively negligible. For example, research has suggested a link between extraversion and working memory (Lieberman, 2000). In short, specific instances of personality-EF links have been identified, but no major effort to chart these relationships has been undertaken.

There are two prime purposes of this paper. The first is to discover the suggestions of the personality construct of need to assess for a variety of cognitive, affective and behavioral outcomes. Because attitudes influence a multitude of mental and behavioral processes, and because need to appraise, predicts a person's inclination to form attitudes, the variable should be speaking out about cognitive, affective and behavioral processes that are correlated with attitudes. Executive functions are significant for objective-directed behavior and have been tied with a number of important constructs like personality. In any case, examining the connections between personality traits and cognitive (here, executive) functioning is a fascinating field. On one hand, it may help us understand what challenges and strengths people of different dispositions may have cognitively. 


\section{Exploring the Relations between Executive Functions and Personality}

A limited number of studies have dealt with personality correlates of executive functions. One recent observation revealed that a composite measure of executive functions was associated with Agreeableness, Openness and Neuroticism (Williams, Suchy \& Kraybill, 2010), whereas another examination using the Big Five as a personality model, explained Extraversion to Vigilance and Openness to be correlated with Fluency (Unsworth, Miller, Lakey, Young, Meeks, Campbell \& Goodie, 2010). Researchers suggest that better Updating/Monitoring was connected with higher Openness and lower Neuroticism. Openness was also positively associated with Cognitive Flexibility (Murdock, Oddi and Bridgett, 2013). Campbell, Davalos, McCabe, and Troup (2011) found that extraversion and executive functions like shifting, updating, and inhibition have been linked to similar neurological substrates. It was found that more extraverted subjects showed different patterns of executive function working than the more introverted subjects. Extraverts executed best on more difficult tasks and on updating tasks. On the other hand, introverts executed best on set shifting tasks. Stringer, Marshall, Pester, Baker, Langenecker, Angers, Frazier, Archer, Kamali, McInnis and Ryan (2014) found Openness to experience came out to be a well-established personality factor and is correlated with cognitive performance.

Recent researches tell us something important about the mechanisms underlying the development of differing personalities. Of more general interest, this study may also provide some answers as to whether certain personality traits could be thought of as more "useful" or beneficial for success in life (as good executive functioning is crucial to many aspects of daily and professional life). In relation to executive functioning, it would appear the best evidence currently exists for high Neuroticism being linked with poorer EF, and higher Openness with better overall EF, the connections may be more specific than that, down to the level of certain sub-aspects of executive functioning. So, executive Control is required to deal with novel situations or when an action plan is needed.

Research also states that various dimensions of trait impulsiveness strongly associated with performance on several executive function tests in healthy young adults (Pietrzak, Sprague \& Snyder, 2008). Rike, Johansen, Ulleberg, Lundqvist and Schanke (2015) explored the relationships between post-injury driving behavior (impulsive personality traits) and self-rating of higher-level functions. They found that baseline perceived executive functions and impulsive personality traits were extensively correlated with driving self-efficacy at follow-up. Research suggests that individuals in the common population with high levels of impulsive personality traits also showed poor executive function (Pietrzak, Sprague \& Snyder, 2008). Krieger and Amador (2014) found between behavioral executive functions scores, cognitive style and personality factors like openness, conscientiousness, extroversion and agreeableness.

Recent researches also concentrate on the relationship of personality traits and executive functions in different problems also. Demir, Ucar, Ulug, Ulusoy, Sevinc and Batur (2002) found the relationship between enzyme activity, personality traits and executive functions. Pignatti and Bernasconi (2013) Cognitive deficits in Eating Disorders have been related to the executive 


\section{Exploring the Relations between Executive Functions and Personality}

function domain. Analysis done by Bergeron and Valliant (2001) stated significant differences in executive functioning and personality, as offender groups revealed poor executive capacity and maladaptive personality characteristics in younger population. In another population, Affrunti, Gramszlo and Woodruff-Borden (2016) examined the cognitive shift domain of executive function, the role of fearful temperament and their interaction on separate dimensions of perfectionism. Results point out those children with higher cognitive shift deficits had major influence of fearful temperament on factors of perfectionism. Puric and Pavlovic (2012) investigates the executive function of shifting and its relationship to personality constructs and intelligence. The results of study throw light on neuroticism, stating that executive functions might play a noteworthy role in determining people's general emotional vulnerability. Adrian, Postal, Moessinger, Rascle, and Charles (2011) considered how executive functions and personality traits are communicated with driving performance among older drivers. Noteworthy associations were observed between poor driving performances and low scores on measures assessing shifting and updating functions.

In the most recent researches, explained the relationship between EF and Borderline Personality Disorder (BPD) in different group. McClure, Hawes and Dadds (2015) explored the relationship between EF and BPD and present evidences of high comorbidity between BPD and attentiondeficit/hyperactivity disorder; though, in spite of a marked increase in research of EF and BPD in recent times, the specific nature of this association remains uncertain. They present a systematic review of this promising evidence base, with respect to researches of subjects identified with $\mathrm{BPD}$ in which EF has been guided in isolation from broader cognitive processes. The precise domains of EF, have been combined with BPD, whether deficits in EF are exceptionally associated with BPD, independent of comorbidity of psychopathology. Gvirts, Harari, Braw, Shefet, Shamay-Tsoory and Levkovitz (2012) inspect executive functions in both, patients of borderline personality disorders and their unaffected parents. They found that borderline personality disorders patients showed deficient in executive function working as compared to healthy subjects in sustained attention, cognitive planning and working memory. Different domains of executive functions such as response inhibition and working memory were considered together with basic cognitive processes in borderline personality disorder (Hagenhoff, Franzen, Koppe, Baer, Scheibel, Sammer, Gallhofer \& Lis, 2013). The error rates were higher and increased more highly in BPD patients depending on working memory load.

A number of studies have suggested that various Executive functions are also related to more personality traits. Empirically, several studies have reported significant relationships between personality and executive functions (Dolan \& Park, 2002; Matheson \& Langdon, 2008). In addition, actions related to antisocial personality disorder for example, aggression (Giancola, 2004) and antisocial behavior (Morgan \& Lilienfeld, 2000) are connected to poor executive functions. The present study conducts a comprehensive examination of executive functions relationships via a latent variable analysis of executive functions and personality in a university sample. 


\section{Exploring the Relations between Executive Functions and Personality}

One limitation with several of the previous studies is that the relationship between executive functions and personality was observed using a single executive functions based task and a sole personality variable, and therefore may not offer the best proof for more general constructs. It is significant, therefore, to study these associations at an underlying level with multiple executive functions and personality measures. Two current observations have inspected the affiliation between personality and executive functions at a covert level. DeYoung, Peterson, and Higgins (2005) established that "Openness" was related to a broad executive functions factor derived from seven tasks. Similarly, Salthouse, Berish, and Siedlecki (2004) stated that a broad executive functions factor was related to Openness and Agreeableness. However, research suggests that executive functions represent a family of related functions rather than a single dominant function, so that it is unclear what aspect of Executive functions is being indexed in these studies.

\section{Rationale of the study}

The connection between personality traits and executive functioning is a fascinating field. On one hand, it may help in understanding what challenges and strengths people of different dispositions may have cognitively. On the other, it may tell us something important about the mechanisms underlying the development of differing personalities. Of more general interest, this study like it may provide some answers as to whether certain personality traits could be thought of as more "useful" or beneficial for success in life (as good executive functioning is crucial to many aspects of daily and professional life).

\section{OBJECTIVES:}

1. To examine the relationship between personality traits and Executive Functions among graduate students.

2. To assess the contribution personality traits as predictor of Executive Functions among graduate students.

\section{Hypotheses:}

1. Personality would be positively related with Executive Functions among graduate students.

2. Personality traits would significantly predict Executive Functions among graduate students.

\section{METHOD}

\section{Sample:}

The study was conducted on a sample of 60 graduate students from M. D. University, Rohtak. The age ranges of the subjects varied from 20 to 30 years. They were selected from various departments and library on the basis of incidental sampling technique who are not suffering from any chronic disease for two month were taken. 


\section{Exploring the Relations between Executive Functions and Personality}

\section{Design:}

The goal of the current study was to examine links between personality traits and executive functions. For this purpose, a correlational design was employed. A correlational research can establish whether two variables tend to be related to each other or not. To find out the main a predictor of personality trait on executive functions among graduates regression method was applied.

\section{Tools:}

On the basis of objectives, following standard measures of personality and executive functions were selected for the data collection:

- The NEO-Five Factor Inventory: It is developed by Costa and McCrae (1992) for adult $(17+)$ men and women without overt psychopathology. It is a 60 items version of the NEOPI-R that is scored for the five domains only. The Hindi version of the inventory was used in the present study. It consists of five 12-item scales that measure each domain and each item consists of five answer choices graded in intensity from (0 to 4) according to the instructions. NEO-FFI has been found to be a useful tool for evaluating five broad domains or dimensions of personality that are used to describe human personality. The Big Five factors are neuroticism $(\mathrm{N})$, extraversion $(\mathrm{E})$, openness $(\mathrm{O})$, agreeableness $\quad(\mathrm{A})$ and conscientiousnesss (C). Two week test-retest reliability is uniformly higher, ranging from .86 to .90 for the five scales (Robin, Fradey, Roberts, \& Trzesniswski, 2001) and internal consistency range from .61 to .86 (Costa \& McCrae, 1992). The reliabilities of the five scales were assessed in term of internal consistencies and test - retest reliability. The alpha coefficient or the individual facet scale ranged from .56 to .81. The full scale coefficient alphas ranged from .86 to .95 (Costa at al. 1991).

- Executive Function Index (EFI) by Spinella (2005): EFI is a subjective measure of executive functioning consisting of 27 items which provide scores on five subscales derived through factor analysis: Organization (ORG), Strategic planning (SP), Empathy (EM), Impulse control (IC), Motivational drive (MD). Each items is to be rated on a five point scale (scores to be assigned from 1 to 5). Studies using self-rated executive function (SREF) measures, such as the EFI, have yielded results that are consistent with other studies using more objective measures such as functional neuro-imaging and objective measures of behavior.

\section{Procedure}

For data collection, all the participants were individually contacted on their respective departments in the university. A cordial rapport was established with all the participants by talking with them generally about their life. After establishment of healthy rapport, they were provided with the response sheets in mixed order. Respondents were asked to read the instructions carefully and requested to attempt all the items. Sufficient time was given to the participants for each tool to read and fill. A rest of 10 minutes was given to the participants between tests to prevent them from fatigue. After completion of the measuring tools, response 


\section{Exploring the Relations between Executive Functions and Personality}

sheets were taken back from the participants and they were thanked for their valuable time and cooperation. The data were analyzed with the help of Pearson's Product Moment method of correlation and Multiple Regression.

\section{RESULTS AND DISCUSSION}

The primary aim of the present study was to find out personality as correlates of executive functions on a sample of 60 graduates. The correlations among components of personality and executive functions are observed by applying Pearson correlation with the help of SPSS 16.0 version.

\section{Correlational Analysis}

In order to examine the degree of association among the variables used in the study correlations between all possible pairs were computed. The following table consists of index of correlation among Personality traits and Executive Functions.

Table 1 expresses the correlation between Personality dimensions and Executive Functions ranges between .36 and .26. The correlations between Factor neuroticism ' $\mathrm{N}$ ' and Executive Functions dimension of impulse control (IC) are -.29. The negative correlations are significant at .05 level. The negative correlation indicates that students who are emotionally reactive and vulnerable to stress, anxiety or depression have less impulse control like self-inhibition, risk taking, and have no social conduct.

Table 1: Coefficient of correlation between dimension of Personality and Executive Functions.

\begin{tabular}{|c|c|c|c|c|c|c|}
\hline & & \multicolumn{5}{|c|}{ Executive Functions } \\
\hline & & $\begin{array}{r}\text { Organization } \\
\text { (ORG) }\end{array}$ & $\begin{array}{l}\text { Strategic } \\
\text { Planning (SP) }\end{array}$ & $\begin{array}{l}\text { Empathy } \\
\text { (EM) }\end{array}$ & $\begin{array}{l}\text { Impulse } \\
\text { Control } \\
\text { (IC) }\end{array}$ & $\begin{array}{l}\text { Motivational } \\
\text { Drive (MD) }\end{array}$ \\
\hline \multirow{5}{*}{ 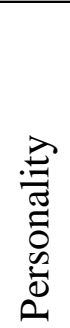 } & $\mathrm{N}$ & -.24 & -.13 & -.04 & $-.29 *$ & -.25 \\
\hline & $\mathrm{E}$ & .06 & $.34 * *$ & .19 & -.06 & $.26^{*}$ \\
\hline & $\mathrm{O}$ & .11 & $.33 *$ & .24 & .01 & -.13 \\
\hline & A & .04 & -.04 & .01 & .10 & -.06 \\
\hline & $\mathrm{C}$ & .18 & $.34 * *$ & $.26^{*}$ & $.34 * *$ & $.36 * *$ \\
\hline
\end{tabular}

Note: ${ }^{*} \mathrm{p}<.05,{ }^{* *} \mathrm{p}<.01$ (Two tailed)

The correlations between Factor ' $E$ ' (extraversion) and Executive Functions dimension on Strategic Planning (SP) and Motivational drive (MD) are .34 and .26 respectively. The correlations between Factor ' $E$ ' and executive functions dimension on Strategic Planning (SP) are significant at .01 level and with Motivational drive (MD) are significant at .05 level. The positive correlation between Factor ' $E$ ' and executive functions dimension on Strategic Planning and Motivational drive indicates that students who are having tendencies of going out, talkative, 


\section{Exploring the Relations between Executive Functions and Personality}

have great social relationship, have tendencies to think ahead, plan, and use strategies and have tendencies to behavioral drive, activity level, and interest in novelty.

The correlations between Factor ' $O$ ' (openness) and executive functions dimension on Strategic Planning (SP) is .33 significant at .05 level. The positive correlation between factor ' $\mathrm{O}$ ' and Strategic planning is indicates that students who are open to experience have tendencies to think ahead, plan, and use strategies. The correlations between factor 'A' (agreeableness) and executive functions dimensions are found non-significant.

The correlations between factor ' $C$ ' (Conscientiousness) and dimensions of executive eunctions i.e. Strategic Planning (SP), Empathy (EM), Impulse Control (IC) and Motivational Drive (MD) are .34, .26, .34 and .36 respectively. The correlations between factor ' $C$ ' and executive functions i.e. Strategic Planning, Impulse Control and Motivational Drive are significant at .01 level. The correlations between factor ' $C$ ' and executive functions i.e. Empathy is significant at .05 level. The positive correlation between Factor ' $C$ ' and Executive Functions i.e. Strategic Planning, Empathy, Impulse Control and Motivational Drive indicates that students who are having trait of self-discipline and act dutifully have the tendencies to think ahead, plan, and use strategies, have tendencies to think for the well-being of others, and a cooperative attitude, selfinhibition and have tendencies to behavioral drive, activity level, and interest in novelty.

\section{Multiple Regression:}

In order to assess the predictability of personality traits stepwise multiple regression was used.

Table: 2 , Summary of Stepwise Multiple Regression Analysis Dependent Variable: Life Satisfaction.

\begin{tabular}{lllllllll}
\hline S. No. & Steps & Variable & $\mathbf{R}$ & $\mathbf{R} 2$ & $\mathbf{R}^{2}$ Change & $\mathbf{B}$ & $\mathbf{F}$ & $\mathbf{P}$ \\
\hline 1 & 1 & Conscientiousness (C) & .47 & .22 & .22 & .82 & 16.00 & .01 \\
\hline
\end{tabular}

Table-2 shows the results of stepwise regression analysis for the dependent measure executive functions in the sample of university students. The predictor measure of Conscientiousness (C) accounts for $22 \%$ of the variance in executive functions and significant at .01 level of probability in students. Results show a notable contribution of Conscientiousness to executive functions in students. It may be interpreted that students who are having trait of self-discipline and act dutifully have the tendencies to think ahead, plan, and use strategies, have tendencies to think for the well-being of others, and a cooperative attitude, Impulse control and have tendencies to behavioral drive, activity level, and interest in novelty.

The results of stepwise regression analysis have clearly revealed that Conscientiousness variable contribute significantly to the prediction of student's executive functions. The results of the present study are supported by the recent researches Bogg and Roberts (2013) stated that 


\section{Exploring the Relations between Executive Functions and Personality}

executive function is a more powerful predictor of two health-related behaviors than the personality trait sphere of conscientiousness. Hall, Fong and Epp (2013) also made clear that executive function, conscientiousness and neuroticism were major predictors of health behavior in age-corrected regression analyses. Buchanan, (2015) revealed that problems of selfreported executive function were seen to associate with low conscientiousness, neuroticism, with medium to large effect sizes.

\section{CONCLUSION}

Overall, these results support the existence of specific links between personality traits and executive functions in individuals. Most prominently, results of the present study signal a new and stimulating line of research concerning the role of executive functioning in shaping at least assured (i.e. conscientiousness) personality traits. There are found significant positive relationship between personality and executive functions among graduate students. Students who are having trait of self-discipline and act dutifully have the ability to Strategic planning, Empathy, Impulse control and Motivational drive and students who are emotionally reactive and vulnerable to stress, anxiety or depression have less impulse control. Results show a notable contribution of Conscientiousness to executive functions i.e. students who are having trait of self-discipline and act dutifully has the ability to Strategic planning, Empathy, Impulse control and Motivational drive.

In general most of the results of the present study maintain the hypotheses and earlier research observations. All the associations between personality and executive functions are found significant. The result of total group explains that the subjects express positive significant associations on extraversion, openness and conscientiousness with executive functions. Personality dimensions i.e. neuroticism is found to be negatively correlated with executive functions. It shows that students who are showing neurotic tendencies have less executive functions. It is also observed that those students who are high on open to experience, extraversion and Conscientiousness are having better executive functions. On the basis of these results, a notable contribution of Conscientiousness to executive functions among students is observed.

\section{IMPLICATION}

Intervention programme for increasing Conscientiousness should be implemented in educational institutions. Subjects high on neuroticism should be given training for impulse control. Strategic planning is associated with openness to experiences, Extraversion and Conscientiousness, thus person high on these dimensions should be recruited for job that requires strategic planning.

\section{REFERENCES}

Adrian, J., Postal, V., Moessinger, M., Rascle, N., \& Charles, A. (2011). Personality traits and executive functions related to on-road driving performance among older drivers. Accident Analysis \& Prevention, 43(5), 1652-1659. 


\section{Exploring the Relations between Executive Functions and Personality}

Affrunti, N. W., Gramszlo, C., \& Woodruff-Borden, J. (2016). Executive function moderates the association between fearful temperament and dimensions of perfectionism. Personality and Individual Differences, 89, 117-122.

Bergeron, T. K., \& Valliant P. M. (2001) Executive Function and Personality in Adolescent and Adult Offenders vs. Non-Offenders. Journal of Offender Rehabilitation, 33(3), 27-45.

Bogg, T. \& Roberts, B. W. (2013). Duel or diversion? Conscientiousness and executive function in the prediction of health and longevity. Journal of Behavioral Medicine, 45(3), 400-401.

Buchanan T. (2015). Self-Report Measures of Executive Function Problems Correlate With Personality, Not Performance-Based Executive Function Measures, in Nonclinical Samples. Psychological Assessment. 2015 Jul 20. [Epub ahead of print]

Campbell, A. M., Davalos, D. B., McCabe, D. P., \& Troup L. J., (2011). Executive functions and extraversion. Personality and Individual Differences, 51(6), 720-725.

Carlson, S. R., Thai, S., \& McLarnon, M. E. (2009). Visual P3 amplitude and selfreported psychopathic personality traits: Frontal reduction is associated with self centered impulsivity. Psychophysiology, 46, 100-113.

Costa, P. T., Jr., \& McCrae, R. R. (1992). Revised NEO Personality Inventory (NEO PI-R) and NEO Five-Factor Inventory (NEO-FFI). Odessa, FLORIDA: Psychological Assessment Resources.

Demir, B., Ucar, G., Ulug, B., Ulusoy, S., Sevinc, I., \& Batur, S. (2002). Platelet Monoamine Oxidase Activity In Alcoholism Subtypes: Relationship To Personality Traits And Executive Functions. Alcohol and Alcoholism. 37(6), 597-602.

DeYoung, C. G., Peterson, J. B., \& Higgins, D. M. (2005). Sources of openness/intellect: Cognitive and neuropsychological correlates of the fifth factor of personality. Journal of Personality, 73, 825-858.

Dolan, M., \& Park, I. (2002). The neuropsychology of antisocial personality disorder. Psychological Medicine, 32, 417-427.

Giancola, P. R. (2004). Executive Functioning and Alcohol-Related Aggression. Journal of Abnormal Psychology, 113, 541-555.

Hagenhoff, M., Franzen, N., Koppe, G., Baer, N., Scheibel, N., Sammer, G., Gallhofer, B., \& Lis, S. (2013). Executive functions in borderline personality disorder. Psychiatry Research, 210 (1), 224-231.

Hall, P. A., Fong, G. T., \& Epp, L. J. (2013). Cognitive and personality factors in the prediction of health behaviors: an examination of total, direct and indirect effects. Journal of Behavioral Medicine, 37(6), 1057-1068.

Hila Z. Gvirts, Hagai Harari, Yoram Braw, Daphna Shefet, Simone G. Shamay-Tsoory, Yechiel Levkovitz (2012). Executive functioning among patients with borderline personality disorder (BPD) and their relatives. Journal of Affective Disorders, 143, (1-3), 261-264.

Krieger, V. \& Amador, J. A. (2014). Executive functions, five-factor model personality dimensions and cognitive style in adolescents. Personality and Individual Differences, 60, S57.

Lieberman, M.D. (2000). Introversion and working memory: Central executive differences. Personality and Individual Differences, 28, 479-486. 


\section{Exploring the Relations between Executive Functions and Personality}

Matheson, S., \& Langdon, R. (2008). Schizotypal traits’ impact upon executive working memory and aspects of IQ. Psychiatry Research, 159, 207-214.

McClure, G., Hawes, D. J., \& Dadds, M. R. (2015). Borderline personality disorder and neuropsychological measures of executive function: A systematic review. Personality and Mental Health. doi: 10.1002/pmh.1320.

Morgan, A. B., \& Lilienfeld, S. O. (2000). A meta-analytic review of the relation between antisocial behavior and neuropsychological measures of executive function. Clinical Psychology Review, 20, 113-156.

Murdock, K. W., Oddi, K. B., \& Bridgett, D. J. (2013). Cognitive correlates of personality: Links between executive functioning and the big five personality traits. Journal of Individual Differences, 34(2), 97-104.

Pietrzak, R. H., Sprague, A., \& Snyder, P. J. (2008). Trait impulsiveness and executive function in healthy young adults. Journal of Research in personality, 42(5), 1347-1351.

Pietrzak, R. H., Sprague, A., \& Snyder, P. J. (2008). Trait impulsiveness and executive function in healthy young adults. Journal of Research in Personality, 42, 1347-1351.

Pignatti, R., \& Bernasconi V. (2013). Personality, clinical features, and test instructions can affect executive functions in Eating Disorders. Eating Behaviors, 14(2), 233-236.

Puric, D., \& Pavlovic, M. (2012). Executive function of shifting: Factorial structure and relations to personality and intelligence domains. Suvremena Psihologija. 15(2), 177-191.

Rike, P., Johansen, H. J., Ulleberg, P., Lundqvist, A., \& Schanke, A. (2015). Exploring associations between self-reported executive functioning, impulsive personality traits, driving self-efficacy, and functional abilities in driver behaviour after brain injury. Transportation Research Part F: Traffic Psychology and Behaviour, 29, 34-47.

Spinella, M. (2005). Self-rated executive function: development of the executive function index. International Journal of Neuroscience, 115(5), 649-667.

Stringer, D., Marshall, D., Pester, B., Baker, A., Langenecker, S. A., Angers, K., Frazier, N., Archer, C., Kamali, M., McInnis, M., \& Ryan, K. A. (2014). Openness predicts cognitive functioning in bipolar disorder. Journal of Affective Disorders, 168, 51-57.

Unsworth, N., Miller, J. D., Lakey, C. E., Young, D. L., Meeks, J. T., Campbell, W. K., \& Goodie, A. S. (2009). Exploring the Relations among Executive Functions, Fluid Intelligence, and Personality. Journal of Individual Differences, 30(4), 194-200.

Unsworth, N., Miller, J. D., Lakey, C. E., Young, D. L., Meeks, J. T., Campbell, W. K., \& Goodie, A. S. (2010). Exploring the relations among executive functions, fluid intelligence, and personality. Journal of Individual Differences, 30(4), 194-200.

Whiteside, S. P., \& Lynam, D. R. (2001). The five factor model and impulsivity: using a structural model of personality to understand impulsivity. Personality and Individual Differences, 30, 669-689.

Williams, P. G., Suchy, Y., \& Kraybill, M. L. (2010). Five-Factor Model personality traits and executive functioning among older adults. Journal of Research in Personality, 44(4), 485-491. 